\title{
AVALIAÇÃO DAS PROPRIEDADES DO BIOSSURFACTANTE FORMULADO PRODUZIDO POR CANDIDA SPHAERICA
}

\author{
J. G. M. BRITO ${ }^{1}$, P. F. CORRÊA ${ }^{1}$, H. S. AMORIM ${ }^{1}$, B.G. FREITAS $^{1}$, R. D. RUFINO ${ }^{1,2}$, J.M. \\ LUNA $^{1,2}$ e L.A. SARUBBO ${ }^{1,2}$ \\ ${ }^{1}$ Universidade Católica de Pernambuco, Centro de Ciências e Tecnologia \\ ${ }^{2}$ Centro de Gestão de Tecnologia e Inovação, CGTI \\ E-mail para contato: julianagabriela_brito@outlook.com
}

\begin{abstract}
RESUMO - O crescente interesse por biossurfactantes é atribuído às características como capacidade de redução da tensão superficial, emulsificação e baixa toxicidade. Neste sentido a Candida sphaerica foi cultivada em meio de 5\% do resíduo de óleo vegetal e $2,5 \%$ de milhocina, durante 144 horas a $200 \mathrm{rpm}$ para a produção de biossurfactante. O biossurfactante produzido foi submetido a um conservante comercial a fim de testar sua estabilidade frente a diferentes variações de $\mathrm{pH}$, temperatura e sal. Após formulação do líquido metabólico contendo o biossurfactante produzido, foram estocadas à temperatura ambiente por 120 dias, onde foram realizados testes de tensão superficial, atividade de emulsificação e capacidade de dispersão. Os resultados obtidos demonstraram que o biossurfactante formulado, apresentou propriedades tensoativas, emulsificantes e dispersantes, em diferentes condições ambientais de $\mathrm{pH}$, temperatura e de sal. Dessa forma a biomolécula apresenta potencial para aplicação industrial.
\end{abstract}

\section{INTRODUÇÃO}

Os surfactantes são compostos químicos constituídos por moléculas anfipáticas contendo porções hidrofílicas e hidrofóbicas que se particionam, preferencialmente, na interface entre fases fluidas que possuem diferentes graus de polaridade e pontes de hidrogênio, como interfaces óleo/água ou ar/água (Fracchia et al., 2012; Banat, 2010). Estas características permitem aos surfactantes reduzir a tensão superficial e interfacial e formar microemulsões onde os hidrocarbonetos possam se solubilizar em água ou onde a água possa se solubilizar em hidrocarbonetos (Ron; Rosenberg, 2002b). Tais propriedades possibilitam uma ampla gama de aplicações industriais envolvendo detergência, emulsificação, lubrificação, capacidade espumante, capacidade molhante, solubilização e dispersão de fases (Marchant; Banat, 2012b).

A Biotecnologia permitiu ampliar os limites de aplicação dos aditivos sintéticos, desenvolvendo novos produtos baseados na capacidade sintética dos micro-organismos. Estas perspectivas, relacionadas aos produtos de elevado interesse industrial, têm conduzido a investigação e o desenvolvimento de novas tecnologias na produção de agentes surfactantes por microrganismos (Stampfli; Nersten, 1995).

Os compostos de origem microbiana que exibem propriedades surfactantes, isto é, diminuem a tensão superficial e possuem alta capacidade emulsificante, são denominados biossurfactantes e consistem em subprodutos metabólicos de bactérias, fungos filamentosos e leveduras (Reddy, 1995).

Nesse sentido, os resíduos industriais têm despertado grande interesse dos pesquisadores como substratos de baixo custo para a produção de biossurfactantes. Muitos biossurfactantes 
têm sido produzidos a partir de substratos agroindustriais, renováveis e de baixo custo. Óleos vegetais, resíduos de fritura de óleos vegetais, resíduos de destilaria de óleos, resíduos da indústria de laticínios (soro de leite), melaço de cana e glicerina têm sido citados na literatura (Gallert; Winter, 2002).

A possibilidade de produção dos biossurfactantes a partir de substratos renováveis e de diferentes espécies microbianas, além da possibilidade de variação de inúmeros parâmetros culturais como tempo de cultivo, velocidade de agitação, $\mathrm{pH}$ do meio e nutrientes adicionados, possibilita a obtenção de compostos com características estruturais e propriedades físicas distintas, o que os tornam comparáveis ou superiores aos surfactantes sintéticos em termos de eficiência, embora os custos de produção ainda não permitam uma maior competitividade com os similares sintéticos (Pacwa-Plociniczak et al., 2011). Outra condição essencial para o uso de biossurfactantes é que eles possam ser produzidos por micro-organismos não patogénicos.

Portanto, o objetivo desse trabalho foi produzir um agente surfactante a partir de Candida sphaerica utilizando resíduos industriais como substratos de baixo custo, bem como formular o biossurfactante com vistas à aplicação dessa biomolécula como aditivo comercial coadjuvante dos processos de remediação de poluentes hidrofóbicos gerados na indústria de petróleo.

\section{MATERIAIS E MÉTODOS}

\subsection{Micro-organismo}

Candida sphaerica, mantida em meio YMA (Yeast Mold Ágar) foi utilizada como micro-organismo produtor do biossurfactante. Repiques foram mensalmente realizados para manter a viabilidade celular.

\subsection{Meios de manutenção e crescimento do inóculo}

A manutenção da levedura foi realizada utilizando-se o meio Yeast Mold Ágar (YMA), com a seguinte composição: extrato de levedura $(0,3 \%)$, D-glicose $(1 \%)$, triptona $(0,5 \%)$, ágar (2\%) Água destilada q.s.p $(100 \mathrm{~mL})$. Os componentes foram solubilizados e esterilizados em autoclave a $121^{\circ} \mathrm{C}$ por 20 minutos. Quando excluído o ágar, constituiu o meio de crescimento, Yeast Mold Broth (YMB).

\subsection{Meio de produção}

As fermentações para produção do biossurfactante foram realizadas em meio formulado com água destilada contendo $5 \%$ do resíduo de óleo vegetal e $2,5 \%$ de milhocina. Após o preparo dos meios, o pH será ajustado para 5,3 com auxílio de uma solução 5,0 M de $\mathrm{NaOH}$ e estes serão autoclavados a $121^{\circ} \mathrm{C}$ por 20 minutos.

\subsection{Preparação do inoculo}

$\mathrm{O}$ inóculo foi padronizado transferindo-se as culturas para um tubo contendo o meio YMA, a fim de se obter uma cultura jovem. Em seguida, a amostra foi transferida para frascos contendo $50 \mathrm{~mL}$ do meio YMB e incubados sob agitação de $200 \mathrm{rpm}$ a $27^{\circ} \mathrm{C}$ durante 24 horas.

\subsection{Produção do biossurfactante}


As fermentações para produção do biossurfactante foram realizadas em frascos de Erlenmeyer com $500 \mathrm{ml}$ de capacidade contendo $100 \mathrm{~mL}$ do meio de produção e incubados com a suspensão celular de $10^{4}$ células $/ \mathrm{mL}$. Os frascos foram mantidos sob agitação orbital de 150 rpm, durante 144 horas, à temperatura de $27^{\circ} \mathrm{C}$.

\subsection{Determinação da tensão superficial}

A tensão superficial foi medida no líquido metabólico livre de células em tensiômetro KSV Sigma 70 (Finland) utilizando-se o anel de NUOY.

\subsection{Estabilização do líquido metabólico com propriedade surfactante}

O líquido metabólico livre de células contendo o biossurfactante produzido foi conservado de acordo com o seguinte procedimento: (1) ao líquido metabólico foi adicionada a concentração de $0,2 \%$ sorbato de potássio. Em seguida, o líquido metabólico tratado conforme o procedimento descrito acima foi estocado à temperatura ambiente ao longo de 120 dias para observação da estabilidade. Testes foram realizados para determinação do tempo de estocagem $\left(0,15,30,45,60,90\right.$ e120 dias) à temperatura ambiente de $28-30^{\circ} \mathrm{C}$, verificando-se a tensão superficial, capacidade de emulsificação e dispersão de composto hidrofóbico em água do mar, conforme descrito abaixo.

\subsection{Determinação da atividade de emulsificação}

Para a determinação da atividade de emulsificação, amostras do líquido metabólico livre de células foram analisadas segundo a metodologia descrita por Cooper e Goldenberg (1987): 1,0 mL de um substrato oleoso foram adicionados a 1,0 mL do líquido metabólico em tubo graduado e a mistura agitada em vortex por 1 minutos. Após 24 horas as emulsões água em óleo foram expressas em centímetros, devido à altura do halo formado.

\subsection{Avaliação da estabilidade do biossurfactante (efeitos do pH, da adição de $\mathrm{NaCl}$, sob aquecimento)}

Os efeitos de diferentes temperaturas $\left(40\right.$ e $\left.50^{\circ} \mathrm{C}\right)$, de diferentes concentrações de $\mathrm{NaCl}$ $(1,3$ e $5 \%)$ e de diferentes pHs (5, 7 e 9) na atividade do biossurfactante foram avaliados no líquido metabólico livre de células para determinação da tensão superficial e da atividade de emulsificação.

\subsection{Experimentos de deslocamento (dispersão) de composto hidrofóbico em água do mar}

A capacidade de dispersão de manchas de derivados de petróleo foi simulada em laboratório contaminando-se amostras de água do mar com óleo de motor. Os testes foram conduzidos pela adição do liquido metabólico livre de células e da solução do biossurfactante ( $\left.1 \frac{2}{2} \mathrm{CMC}, \mathrm{CMC}\right) 10 \mu \mathrm{L}$ em $15 \mu \mathrm{L}$ do óleo motor. Os resultados foram observados visualmente. 


\section{RESULTADOS E DISCUSSÃO}

\subsection{Avaliação da estabilidade do biossurfactante produzido relacionada à tensão superficial}

A redução da tensão superficial ou interfacial é considerada um dos principais parâmetros para detecção de um composto tensoativo em um determinado meio (Luna et al., 2013).

O líquido metabólico contendo o biossurfactante produzido por $C$. sphaerica apresentou uma tensão superficial praticamente estável, ao se adicionar o conservante a uma concentração de $0,2 \%$ de sorbato, apresentando valores de tensão superficial $25 \mathrm{mN} / \mathrm{m}$ quando submetido à diferentes variações de $\mathrm{pH}$, temperatura e $\mathrm{NaCl}$ (Figura 1).

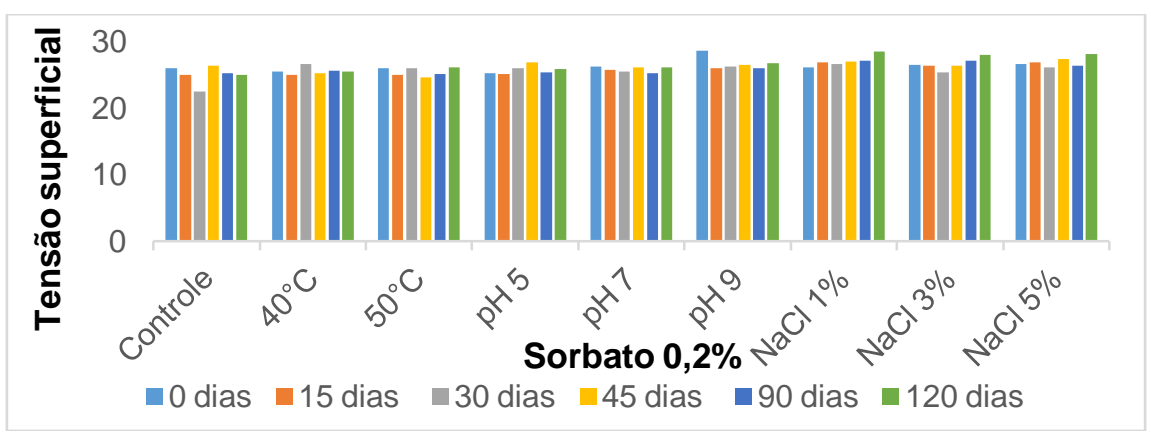

Figura 1- Tensões superficiais do biossurfactante produzido por Candida sphaerica sob conservação com adição de sorbato de potássio a $0,2 \%$ durante 120 em diferentes condições: temperatura $\left(40\right.$ e $\left.50^{\circ} \mathrm{C}\right) ; \mathrm{pH}(5,7$ e 9$)$ e salinidade $(1,3$ e $5 \%)$.

\subsection{Estabilidade do biossurfactante relacionada à capacidade de emulsão}

Uma emulsão é formada quando uma fase líquida encontra-se dispersa como gotas microscópicas em uma outra fase líquida contínua (Desai; Banat, 1997). Quando um líquido é disperso em outro, as pequenas gotas formadas promovem uma grande quantidade de área interfacial e superficial. Na presença de surfactantes, as emulsões formadas podem permanecer estáveis através da redução da tensão interfacial e da redução do grau de coalescência. A estabilidade de uma emulsão está relacionada, assim, ao comportamento do equilíbrio da fase óleo/água/surfactante formada pela ação deste último (Urum; Pekdemir, 2004).

O índice de emulsificação do biossurfactante produzido por C. sphaerica contendo $0,2 \%$ de conservante foi determinada para vários substratos imiscíveis em água: óleo motor, óleo de milho e óleo de soja.

Nos testes para determinação do índice de emulsificação foi observado que os melhores percentuais de emulsificação foram obtidos para o óleo de motor, em torno de $80 \%$ (Figura 2). Quando o biossurfactante conservado foi submetido a variações de $\mathrm{pH}$, houve uma redução no índice de emulsificação nos pHs 7 e 9, enquanto que no pH 5 foi observada uma redução no índice de emulsificação no quadragésimo quinto dia de experimento. Para as concentrações de $\mathrm{NaCl}$ e variações de temperaturas (Figura 2), observou-se que o biossurfactante permaneceu praticamente estável. 


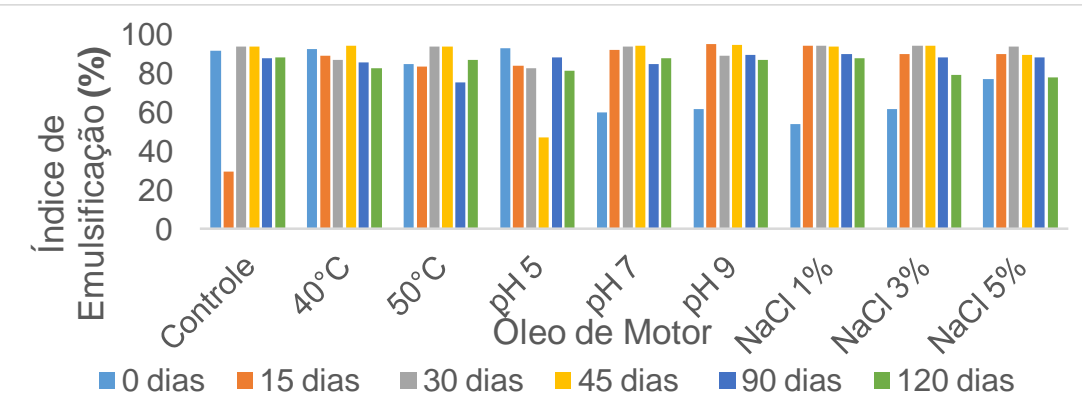

Figura 2 - Índice de emulsificação do biossurfactante produzido contendo sorbato de potássio a $0,2 \%$ utilizando óleo de motor variando: $\mathrm{pH}, \mathrm{NaCl}$ e temperatura.

Quando o líquido metabólico foi submetido a variações de $\mathrm{pH}$ (Figura 3), observou-se que houve uma diminuição no índice de emulsificação nos pHs 5 e 7 , enquanto que no pH 9 foram observados os melhores percentuais de emulsificação.

Para as concentrações de $\mathrm{NaCl}$, observou-se que os melhores percentuais de emulsificação para o óleo de soja foi no decimo quinto dia de experimento, independente da concentração de $\mathrm{NaCl}$ (Figura 3), enquanto que para a variação da temperatura foi observada uma redução na estabilidade da emulsificação na temperatura de $50^{\circ} \mathrm{C}$ (Figura 3).

Esses resultados sugerem que a atividade de emulsificação depende da afinidade do biossurfactante com os substratos hidrocarbonados, que envolve a interação direta com o próprio hidrocarboneto, do que da tensão superficial do meio (Luna et al., 2013).

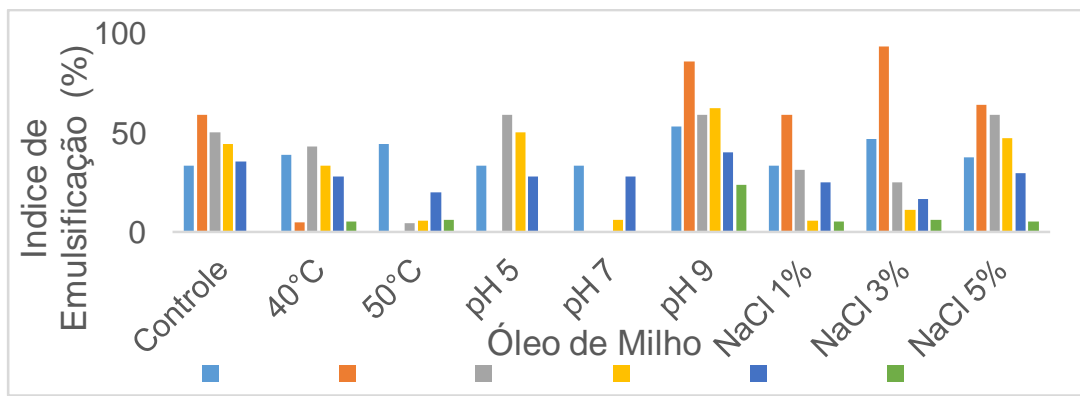

Figura 3 - Índice de emulsificação do biossurfactante produzido contendo sorbato de potássio a 0,2\% utilizando óleo de milho variando: $\mathrm{pH}, \mathrm{NaCl}$ e temperatura

Quando o líquido metabólico foi submetido a variações de $\mathrm{pH}$ (Figura 3), observou-se que os melhores percentuais de emulsificação foram obtidos em pH 9.

Para as concentrações de $\mathrm{NaCl}$, observou-se que o biossurfactante não apresentou emulsificação para o óleo de milho no decimo quinto dia de experimento quando adicionou-se $1 \%$ de $\mathrm{NaCl}$. Já na concentração de $3 \%$ de $\mathrm{NaCl}$, houve uma redução no índice de emulsificação no quadragésimo quinto dia de experimento quando comparado ao controle. Para a condição contendo $5 \%$ de $\mathrm{NaCl}$ o biossurfactante apresentou o melhor percentual de emulsificação de 47,06\% no trigésimo dia de experimento (Figura 3).

Com relação a variação da temperatura, foi observada uma redução na emulsificação para óleo de soja no quadragésimo quinto dia de experimento para as temperaturas de 40 e $50^{\circ} \mathrm{C}$, quando comparado ao controle. 


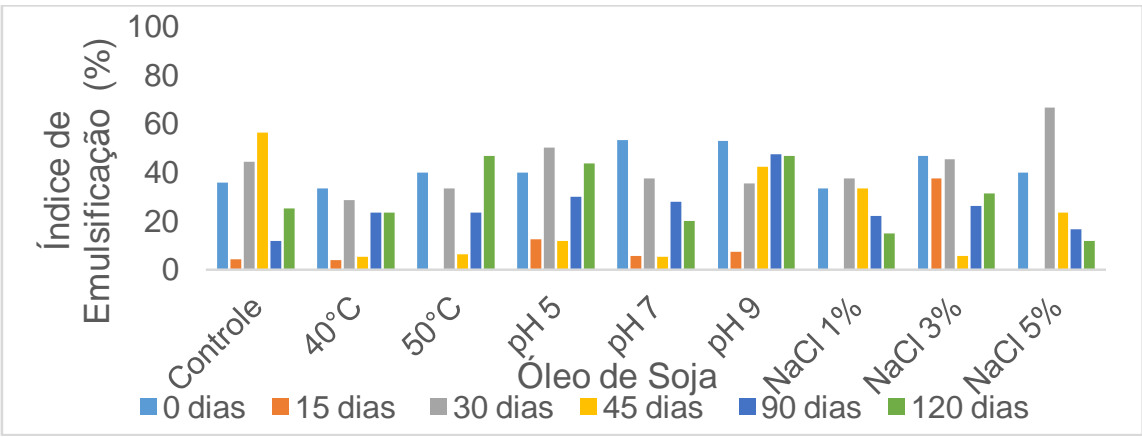

Figura 4 -Índice de emulsificação do biossurfactante produzido contendo sorbato de potássio a $0,2 \%$ utilizando óleo de soja variando: $\mathrm{pH}, \mathrm{NaCl}$ e temperatura.

\subsection{Estabilidade do biossurfactante relacionada à dispersão de óleo em agua do mar}

Outra importante característica dos biossurfactantes é a atividade de dispersão, que é o processo no qual o hidrocarboneto é disperso na fase aquosa como gotas emulsificadas muito pequenas. As emulsões não são estáveis termodinamicamente. Contudo, elas podem permanecer estáveis por períodos significantes de tempo em função de restrições cinéticas. A dispersão está relacionada à tensão interfacial e à concentração do surfactante e difere do deslocamento uma vez que o processo de deslocamento está relacionado apenas à tensão interfacial entre as fases aquosa e hidrofóbica, sem a formação de emulsões (Bai et al., 1997).

As Figuras 5, 6 e 7 ilustram a capacidade do biossurfactante de $C$. sphaerica em dispersar o óleo de motor quando utilizado em diferentes proporções em relação ao óleo derramado (1:2; $1: 8$ e 1:25 vol/vol biossurfactante bruto:óleo), sob influência da variação do $\mathrm{pH}$, da temperatura e na presença de $\mathrm{NaCl}$.

Na Figura 5 observou-se que a variação do pH não alterou o desempenho do líquido metabólico em relação aos índices de dispersão alcançados quando comparados ao controle e o melhor percentual de dispersão foi obtido no trigésimo dia de experimento.

Em relação aos testes com adição de $\mathrm{NaCl}$, os resultados demonstraram que o percentual de dispersão permaneceu praticamente estável. Com relação à variação da temperatura, observou-se que o biossurfactante formulado permaneceu estável (Figura 5).

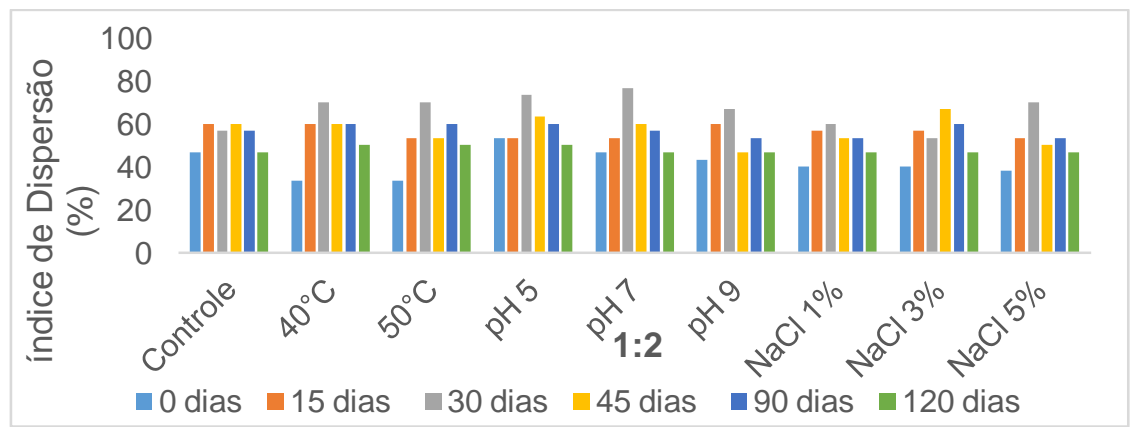

Figura 5 - Índice de dispersão do biossurfactante utilizando de óleo motor na proporção de 1:2 (vol/vol) em relação às variações de $\mathrm{pH}, \mathrm{NaCl}$ e temperatura. 
Pode-se observar que o biossurfactante testado não apresentou uma redução na sua atividade dispersante quando comparado com o controle em todas as variações testadas. Os maiores valores de dispersão foram observados no trigésimo dia de experimento (Figura 6).

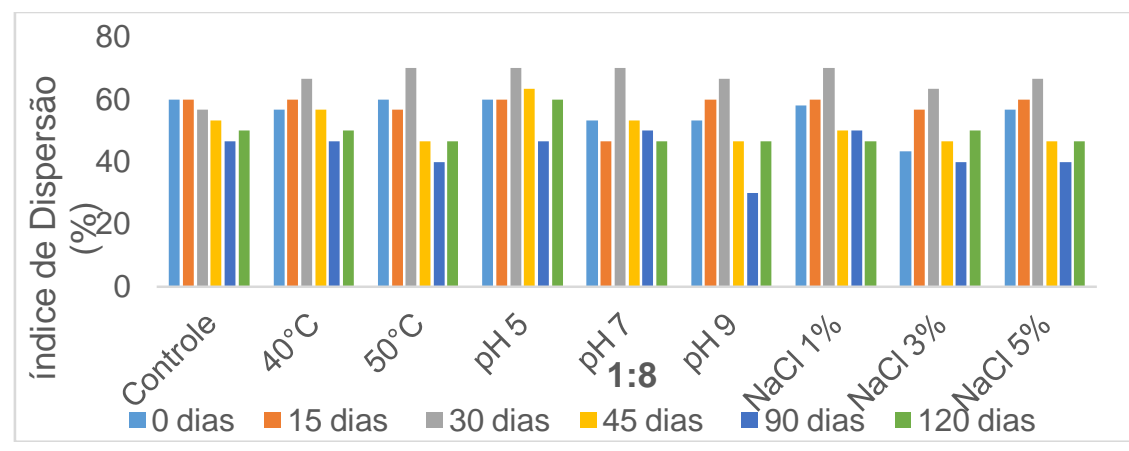

Figura 6 - Índice de dispersão do biossurfactante utilizando de óleo motor na proporção de 1:8 (vol/vol) em relação às variações de $\mathrm{pH}, \mathrm{NaCl}$ e temperatura.

Observou-se que houve uma uma redução na atividade dispersante do líquido metabólico contendo $0,2 \%$ de sorbato de potássio quando submetido as variações de pH 7 e 9 no nonagésimo dia do experimento (Figura 7).

Com relação à variação da concentração de $\mathrm{NaCl}$, foi observado que a atividade dispersante permaneceu praticamente estável (Figura 7).

O liquido metabólico contendo $0,2 \%$ de sorbato foi submetido à variação da temperatura, onde se pode observar que houve uma redução na atividade de dispersão na temperatura de $50^{\circ} \mathrm{C}$ quando comparado ao controle.

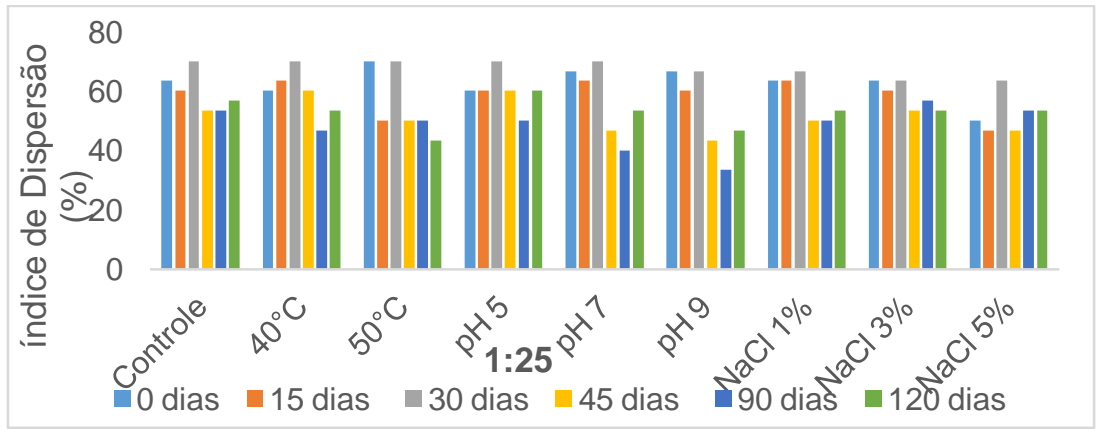

Figura 7 - Índice de dispersão do biossurfactante utilizando de óleo motor na proporção de 1:25 (vol/vol) em relação às variações de $\mathrm{pH}, \mathrm{NaCl}$ e temperatura.

\section{REFERÊNCIAS BIBLIOGRÁFICAS}

CALVO, C.; MANZANERA, M.; SILVA-CASTRO, G.A.; UAD, I.; GONZÁLEZ-LOPÉZ, J. Application of Bioemulsifiers in Soil Bioremediation Processes: Future Prospects. Sci. total environ., v. 407, p.3634-3640, 2009. 
BAI, G.; BRUSSEAU, M.L.; MILLER R.M. Biosurfactant-enhanced removal of residual hydrocarbon from soil. J. contam. Hydrol., v. 25, p.157-170, 1997.

BANAT, I M. Microbial biosurfactants production, applications. Appl. Microbiol. Biotechnol., v. 87, p.427-444, 2010.

DESAI, I. M.; BANAT. Microbiology Molecular Biology. Rev., v.61, p. 47-64, 1997.

FRACCHIA, L.; CAVALLO, M.; GIOVANNA MARTINOTTI; M., BANAT, I.M. Biosurfactants and bioemulsifiers biomedical and related applications - Present Status and Future Potentials, Biomedical Science, Engineering and Technology, Editora Dhanjoo N. Ghista p. 325-370, 2012.

GALLERT, C. WINTER, J. Solid and liquid residues as raw materials for biotechnology. Naturwissenschaften., v. 89, p. 483-496, 2002.

LUNA, J. M., RUFINO, R. D., SARUBBO, L. A., CAMPOS-TAKAKI, G. M., Characterization, surface properties and biological activity of a biosurfactant produced from industrial waste by Candida sphaerica UCP0995 for application in the petroleum industry. Colloids surf B., p. 36, 2013.

MARCHANT, R.; BANAT, I.M. Microbial biosurfactants: challenges and opportunities for future exploitation. Trends Biotechnol., v. 11, p. 558-565, $2012 \mathrm{~b}$.

PACWA-PLOCINICZAK, M.; PLAZA, G.A.; PIOTROWSKA-SEGET, Z.; CAMEOTRA, S.S. Environmental Applications of Biosurfactants: Recent Advances. Intern. J. Mol. Science., v. 13, 633-654, 2011.

REDDY, C. A. The potential for white-rot fungi in the treatment of pollutants. Envinon. Biotechnol., v. 6, p. 320-328, 1995.

RON, E. Z.; ROSENBERG, E. Natural roles of biosurfactants. Z. Naturforsch., v. 3, p. 229236, $2002 b$.

STAMPFLI, L.; NERSTEN, B. Emulsifiers in bread making. Food Chemistry., v. 52, p. 353360, 1995.

URUM, K.; PEKDEMIR, T.; ROSS, D. et al. Evaluation of biosurfactants for crude oil contaminated soil washing. Chemosphere., v.9, p. 1139-1150, 2004. 